\title{
HAMBATAN YANG DIALAMI GURU BK UNTUK MELAKSANAKAN INSTRUMEN NON-TES DALAM PELAYANAN BK DAN USAHA MENGATASINYA
}

\author{
Rina Suryani, Azrul Said, Indah Sukmawati \\ Program Studi Bimbingan dan Konseling, University Negeri Padang, Sumatera Barat, \\ Indonesia. Korespondensi: Jl. Prof. Dr. Hamka, Air Tawar, Padang. \\ Email: rinaasuryani@gmailcom
}

\section{Article Info}

History of Article

Submited Maret 2019

Accepted March 2019

Published March 2019

\section{Key Word \\ Guidance and counseling \\ teachers obstruction, \\ non-test instrument}

\section{Kata Kunci}

Konseling Kelompok, Latihan Assertif, Perilaku Asertif

\begin{abstract}
Guidance and counseling teachers assignment in school is to provide optimum service according to the needs of students. Non-test instrument is one of the types of support activities to reveal the condition of the students as they are. This research is aimed to describe internal and external obstruction from the self and effort by guidance and counseling teachers to overcome obstruction to will do nontest instruments in the guidance and counseling service in school. This research is classified into quantitative research in descriptive type. This research sample are 26 guidance and counseling teachers of Junior High School in Padang city accredited $A$. The research instrument is questionnaire. The findings of the research revealed: the implementation of the non-test instruments have not been fully, because internal and external obstruction from the self guidance and counseling teacher and the average guidance and counseling teachers has tried to overcome these obstruction.
\end{abstract}

\begin{abstract}
Abstrak
Tugas guru BK di sekolah adalah memberikan pelayanan yang optimal sesuai dengan kebutuhan siswa. Instrumen non-tes merupakan salah satu jenis kegiatan pendukung yang digunakan untuk mengungkap kondisi siswa sebagaimana adanya. Penelitian ini bertujuan mendeskripsikan hambatan yang berasal dari dalam dan luar diri serta usaha guru BK mengatasi hambatan untuk melaksanaan instrumen non-tes dalam pelayanan BK di sekolah. Penelitian ini menggunakan pendekatan kuantitatif jenis deskriptif. Sampel penelitian ini adalah 26 orang guru BK SMP Negeri Kota Padang yang berakreditasi A. Instrument penelitian berupa angket. Temuan hasil penelitian mengungkapkan : pelaksanaan instrumen nontes belum terlaksana sepenuhnya bisa saja dikarenakan hambatan yang berasal dari dalam atau luar diri guru BK dan rata-rata guru BK telah melakukan usaha mengatasi hambatan tersebut.
\end{abstract}

\section{Citation Info}

Suryani, R., Said, A., dan Sukmawati, I. (2019). Hambatan Yang Dialami Guru BK Untuk Melaksanakan Instrumen Non-Tes Dalam Pelayanan BK dan Usaha Mengatasinya. In Biblio Couns: Jurnal Kajian Konseling dan Pendidikan, 2(01), 33-40. 


\section{PENDAHULUAN}

Pelayanan bimbingan dan konseling tidak dapat dipisahkan dalam penyelenggaraan pendidikan di sekolah dikarenakan pelayanan bimbingan dan konseling merupakan salah satu bagian penting dalam proses pendidikan. Dalam panduan pengembangan diri (2006:4) dijelakan bahwa "bimbingan dan konseling adalah pelayanan bantuan untuk peserta didik, baik secara perorangan maupun kelompok, agar mandiri dan berkembang optimal, dalam pengembangan kehidupan pribadi, kehidupan sosial, kemampuan belajar dan perencanaan karir, melalui berbagai jenis layanan dan kegiatan pendukung, berdasarkan norma-norma yang berlaku".

Pelaksana layanan bimbingan dan konseling di sekolah saat ini disebut dengan istilah guru BK. Salah satu tugas guru BK di sekolah adalah melaksanakan kegiatan pendukung merupakan salah satu unsur penting yang terkandung dalam BK pola 17.

Salah satu jenis kegiatan pendukung adalah Aplikasi Instrumentasi (AI). Panduan Pengembangan Diri (2006:7) menjelaskan bahwa aplikasi instrumentasi yaitu kegiatan mengumpulkan data tentang diri peserta didik dan lingkungannya, melalui aplikasi berbagai instrumen, baik tes maupun non-tes. Sementara, Prayitno (2006:3) menjelaskan bahwa tujuan umum aplikasi instrumentasi adalah diperolehnya data hasil pengukuran terhadap kondisi tertentu klien.

Instrumen non-tes merupakan salah satu jenis pengumpulan data yang dapat digunakan oleh guru BK agar proses pelayanan BK di sekolah dapat terlaksanan dengan baik.

Angket merupakan salah satu jenis instrumen non-tes yang digunakan untuk mendapatkan keterangan tentang sejumlah hal. Sosiometri juga tidak kalah pentingnya dibandingkan angket. Sosiometri dapat digunakan sebagai pembantu pengungkap permasalahan siswa dalam hubungan sosial kelompok dengan teman di sekolah.

Selain angket dan sosiometri juga terdapat jenis instrumen non-tes lainnya yang dikenal dengan Alat Ungkap Masalah (AUM). AUM terbagi atas dua jenis, yaitu AUM UMUM dan AUM PTSDL. AUM UMUM digunakan untuk mengungkap permasalahan-permasalahan umum yang dialami oleh siswa. Sedangkan AUM PTSDL mengungkap permasalahan yang dialami siswa dalam belajar.

Data dari hasil pelaksanaan instrumen non-tes ini dapat dikombinasikan oleh guru BK dengan data-data lainnya sehingga dapat memberikan manfaat yang sangat besar dalam pemberian layanan BK di sekolah

Pelaksanaan instrumen non-tes hendaknya selalu dilaksanakan dan dijadikan program rutin dalam pelayanan bimbingan dan konseling di sekolah. Karena melalui instrumen non-tes inilah guru BK dapat mengetahui kondisi siswanya sebagaimana apa adanya sehingga pelayanan yang diberikan tepat dan sesuai dengan kondisi siswa.

Namun, kenyataan yang ditemukan saat melakukan PLBK di SMP N 25 Padang bahwa pelaksanaan instrumen non-tes belum terlaksana sepenuhnya dikarenakan berbagai hambatan yang dihadapi oleh guru BK di sekolah. Hambatan 
tersebut dapat berasal dari dalam diri guru BK itu sendiri dan dapat juga berasal dari luar diri guru BK.

Berdasarkan penelitian Jefi Rangga Permaga (2012:42), diketahui bahwa pelaksanaan instrumen non-tes oleh guru BK dalam pemberian layanan BK dapat digambarkan bahwa $42 \%$ guru BK ada melakukan pelaksanaan instrumen non-tes dalam pemberian layanan BK di sekolah dan $58 \%$ guru BK yang tidak ada melakukan pelaksanaan instrumen non-tes dalam pemberian layanan BK. Artinya, guru BK belum sepenuhnya melaksanakan instrumen non-tes dalam pelayanan BK di sekolah.

Pada tanggal 14 Mei 2012, dilakukan wawancara dengan 3 orang guru BK di SMP N 25 Padang, diketahui bahwa mereka jarang melaksanakan instrumeninstrumen non-tes dalam pemberian layanan BK di sekolah.

Kendala utama guru BK untuk melaksanakan instrumen non-tes dalam pelayanan BK di sekolah bisa saja datang dari dalam diri guru BK seperti faktor terbatasnya kemampuan dan keterampilan guru BK untuk melaksanakan instrumen non-tes dalam pelayanan BK di sekolah, sedangkan datang dari luar diri guru BK seperti terkendala dengan keterbatasan waktu di kelas, kurangnya sarana dan prasarana seperti buku AUM beserta lembar jawabannya yang tidak disediakan oleh sekolah dan kurangnya dukungan dari personil sekolah lainnya mengenai pelaksanaan instrumen non-tes dalam pelayanan BK di sekolah.

Selanjutnya pada tanggal 02 Juni 2012, dilakukan wawancara dengan 7 orang siswa kelas VIII SMP N 25 Padang. Berdasarkan hasil wawancara terungkap bahwa dari beberapa jenis instrumen non-tes yaitu pengamatan, wawancara, catatan anekdot, sosiometri, inventori (AUM UMUM, AUM PTSDL), angket, otobiografi dan skala penilaian, mereka hanya pernah diberikan angket mengenai biodata pribadi siswa diawal kelas VIII dan sosiometri yang diadministrasikan oleh mahasiswa PL pada semester I. Berdasarkan hal tersebut peneliti ingin mengungkap "Hambatanhambatan yang dialami guru BK untuk melaksanakan instrumen non-tes dalam pelayanan BK di sekolah dan usaha mengatasinya.

\section{METODOLOGI PENELITIAN}

Penelitian ini menggunakan metode kuantitatif dengan pendekatan analisis deskriptif. Populasi penelitian ini adalah seluruh guru BK yang mengajar di SMP Negeri Kota Padang yang berjumlah 108 orang, sedangkan sampel dalam penelitian ini berjumlah 26 orang yang diambil menggunakan teknik Cluster Sampling, yang didasarkan atas sekolah dengan akreditasi A. Instrumen yang digunakan untuk mengumpulkan data dalam penelitian ini adalah angket. Jenis angket yang digunakan dalam penelitian ini adalah angket tertutup dengan menggunakan skala Guttman dengan dua alternatif pilihan jawaban yaitu "ya" dan "tidak".

\section{HASIL}

Berdasarkan hasil pengolahan data, maka hasil penelitian ini dapat digambarkan sebagai berikut : 
Tabel 1. Rekapitulasi Hambatan-Hambatan yang Dialami Guru BK untuk Melaksanakan Instrumen Non-Tes dalam Pelayanan BK di Sekolah dan Usaha Mengatasinya

\begin{tabular}{clcc}
\hline \multirow{2}{*}{ No. } & \multicolumn{1}{c}{ Aspek } & \multicolumn{2}{c}{ Persentase Jawaban } \\
\cline { 3 - 4 } & & Ya & Tidak \\
\cline { 3 - 4 } 1. & $\begin{array}{l}\text { Hambatan yang berasal dari } \\
\text { dalam diri Guru BK }\end{array}$ & 9 & 91 \\
\hline 2. & $\begin{array}{l}\text { Hambatan yang berasal dari } \\
\text { luar diri Guru BK }\end{array}$ & 13,2 & 86,8 \\
\hline 3. & Usaha mengatasi hambatan & 97,8 & 2,2 \\
\hline
\end{tabular}

Berdasarkan tabel di atas dapat dilihat bahwa rata-rata sebanyak $9 \%$ guru BK menyatakan ya mengalami hambatan yang berasal dari dalam diri untuk melaksanakan instrumen non-tes dalam pelayanan BK di sekolah sedangkan ratarata sebanyak $13,2 \%$ guru BK menyatakan ya mengalami hambatan yang berasal dari luar diri untuk melaksanakan instrumen non-tes dalam pelayanan BK di sekolah dan rata-rata guru BK sudah melakukan berbagai usaha mengatasi hambatan untuk melaksanakan instrumen non-tes, namun masih ada sebanyak 2,2\% guru BK yang tidak melakukan usaha mengatasi hambatan untuk melaksanakan instrumen non-tes dalam pelayanan BK di sekolah.

\section{PEMBAHASAN}

\section{Hambatan yang Berasal dari Dalam Diri Guru BK untuk Melaksanakan Instrumen Non-Tes dalam Pelayanan BK di Sekolah}

Berdasarkan hasil penelitian yang dilakukan, diketahui bahwa hambatan paling dominan yang berasal dari dalam diri guru BK yang sudah memberikan angket dalam pelayanan BK di sekolah adalah sulit mengadministrasikan angket karena sulit menjelaskan petunjuk pengisian angket kepada siswa (19,2\%). Selain itu, guru BK juga sulit mengolah jawaban angket karena kurang terampil dalam mengolah secara manual $(7,7 \%)$.

Saat pengadministrasian angket, hal yang dilakukan oleh guru BK menurut Nana Sudjana (2011:71) adalah menjelaskan petunjuk atau cara pengisian angket supaya tidak terjadi kesalahan, kalau perlu berikan contoh kepada responden. Hal ini seyogyanya sangat diperlukan agar responden tidak mengalami kebingungan dalam pengisian angket.

Selanjutnya, hambatan paling dominan yang berasal dari dalam diri guru BK yang sudah melaksanakan sosiometri dalam pelayanan BK di sekolah adalah sulit mengolah jawaban sosiometri karena kurang terampil menggunakan program komputer $(68,4 \%)$. Selain itu, guru BK juga sulit mengadministrasikan sosiometri 
karena sulit menjelaskan petunjuk pengisian sosiometri kepada siswa $(15,8 \%)$. Sedangkan hambatan paling dominan yang berasal dari dalam diri guru BK yang belum melaksanakan sosiometri dalam pelayanan BK di sekolah adalah sulit mengolah jawaban sosiometri karena kurang terampil menggunakan program komputer $(71,4 \%)$. Selain itu, guru BK juga sulit mengadministrasikan sosiometri karena sulit menjelaskan petunjuk pengisian sosiometri kepada siswa $(28,6 \%)$.

Menurut Prayitno (2006:14) bahwa pengolahan dengan menggunakan program komputer dilakukan dengan memasukkan jawaban responden ke dalam program komputer yang dimaksud yaitu software program pengolahan sosiometri. Untuk dapat menggunakan software tersebut, guru BK dapat mempelajarinya orang yang ahli dibidang ini.

Kemudian, hambatan paling dominan yang berasal dari dalam diri guru BK yang belum memberikan AUM UMUM dalam pelayanan BK di sekolah adalah sulit mengolah jawaban AUM UMUM karena kurang terampil menggunakan program komputer (73,1\%). Selain itu, guru BK juga sulit mengadministrasikan AUM UMUM karena sulit menjelaskan petunjuk pengisian AUM UMUM kepada siswa (26,9\%).

AUM UMUM terdiri dari beberapa format. "Setiap format AUM UMUM tersebut memiliki buku AUM UMUM, lembar jawaban dan dilengkapi dengan software program tersendiri" (Gantina Komalasari, dkk, 2011:140). Oleh sebab itu, hendaknya setiap guru BK memiliki kemampuan dalam menggunakan software ini agar pengolahan AUM UMUM dapat lebih cepat dan mudah.

Selanjutnya, hambatan paling dominan yang berasal dari dalam diri guru BK yang belum memberikan AUM PTSDL dalam pelayanan BK di sekolah adalah sulit mengolah jawaban AUM PTSDL karena kurang terampil menggunakan program komputer (76,9\%). Selain itu, guru BK juga sulit mengadministrasikan AUM PTSDL karena sulit menjelaskan petunjuk pengisian AUM PTSDL kepada siswa $(23,1 \%)$.

Menurut Gantina Komalasari, dkk (2011:149) bahwa salah satu kelebihan penggunaan AUM PTSDL yaitu tersedinya software program pengolahan AUM PTSDL yang akan mempermudah dan mempercepat konselor dalam melakukan proses pengolahan AUM PTSDL sehingga hasil AUM PTSDL dapat digunakan sebagai landasan penetapan bimbingan dan konseling belajar yang sesuai dengan kondisi dan kebutuhan siswa.

Jadi, dapat disimpulkan bahwa dari kesemua instrumen non-tes yang telah dijelaskan sebelumnya, diketahui hambatan yang berasal dari dalam diri guru BK untuk melaksanakan instrumen non-tes dalam pelayanan BK di sekolah adalah kurang terampil dalam menggunkan program kompter dan sulit menjelaskan petunjuk pengisian instrumen non-tes kepada siswa.

\section{Hambatan yang Berasal dari Luar Diri Guru BK untuk Melaksanakan Instrumen Non-Tes dalam Pelayanan BK di Sekolah}

Temuan penelitian mengungkap bahwa bahwa hambatan paling dominan yang berasal dari luar diri guru BK yang sudah memberikan angket dalam pelayanan BK di sekolah adalah sulit memberikan angket karena tidak tersedianya waktu yang 
terjadwal untuk pelayanan BK di kelas (53,8\%). Selain itu, guru BK juga sulit memberikan angket karena terbatasnya waktu pelayanan BK di kelas $(53,8 \%)$.

Tidak semua sekolah memiliki jam tatap muka yang terjadwal untuk pelayanan BK di kelas. Sementara, pemberian angket harus dilaksanakan kepada siswa secara tatap muka. Dengan demikian, guru BK hendaknya menjalin kerjasama dengan guru mata pelajaran untuk bisa mendapatkan sedikit waktu tatap muka dengan siswa. Oleh karena itu, dalam penyususnan angket hendaklah jangan terlalu banyak atau terlalu panjang. Sebab "salah satu ciri kwesioner/angket yang tidak baik adalah terlalu panjang" (Izaak Latunussa, 1988:111).

Selanjutnya hambatan paling dominan yang berasal dari luar diri guru BK yang sudah melaksanakan sosiometri dalam pelayanan BK di sekolah adalah sulit melaksanakan sosiometri karena tidak tersedianya waktu yang terjadwal untuk pelayanan BK di kelas (42,1\%). Selain itu, guru BK juga sulit melaksanakan sosiometri karena terbatasnya waktu pelayanan BK di kelas (42,1\%). Sedangkan hambatan paling dominan yang berasal dari luar diri guru BK yang belum melaksanakan sosiometri dalam pelayanan BK di sekolah adalah sulit melaksanakan sosiometri karena tidak tersedianya waktu yang terjadwal untuk pelayanan BK di kelas $(85,7 \%)$. Selain itu, guru BK juga sulit melaksanakan sosiometri karena terbatasnya waktu pelayanan BK di kelas $(85,7 \%)$.

Menurut Soetjipto (1994:112) salah satu keterbatasan yang dimiliki oleh guru BK adalah kurangnya waktu untuk bertatap muka dengan siswa. Hal inilah yang menjadi hambatan bagi guru BK untuk melaksanakan sosiometri sebab pelaksanaan sosiometri memerlukan waktu bertatap muka dengan siswa untuk melaksanakan kesemua tahap pengadministrasian sosiometri.

Kemudian, hambatan paling dominan yang berasal dari luar diri guru BK yang belum memberikan AUM UMUM dalam pelayanan BK di sekolah adalah sulit memeberikan AUM UMUM karena tidak tersedianya waktu yang terjadwal untuk pelayanan BK di kelas (46,2\%). Selain itu, guru BK juga sulit memberikan AUM UMUM karena terbatasnya waktu pelayanan BK di kelas (46,2\%).

Menurut Gantina Komalasari, dkk (2011:132) bahwa "untuk mengerjakan AUM UMUM pada umumnya diperlukan waktu 50-60 menit". Oleh karena itu, untuk dapat memberikan AUM UMUM kepada siswa, hendaklah disediakan waktu minimal 1 jam tatap muka dengan siswa.

Selanjutnya, hambatan paling dominan yang berasal dari luar diri guru BK yang belum memberikan AUM PTSDL dalam pelayanan BK di sekolah adalah sulit memeberikan AUM PTSDL karena tidak tersedianya waktu yang terjadwal untuk pelayanan BK di kelas (46,2\%). Selain itu, guru BK juga sulit memberikan AUM PTSDL karena terbatasnya waktu pelayanan BK di kelas (46,2\%).

Gantina Komalasari, dkk (2011:151) menjelasakan bahwa "pengerjaan AUM PTSDL tidak memiliki batas waktu, akan tetapi peserta didik diminta dengan teliti, sungguh-sungguh, cepat, dan tidak membuang waktu". Hal ini berbanding terbalik dengan waktu yang disediakan untuk pelayanan BK di sekolah sehingga untuk dapat mengadministrasikan AUM PTSDL kepada siswa, guru BK harus bekerjasama 
dengan guru mata pelajaran dalam hal waktu pelaksanaan ataupun melaksanakannya disaat guru mata pelajaran ada yang tidak hadir.

Jadi, dapat disimpulkan bahwa dari kesemua instrumen non-tes yang telah dijelaskan sebelumnya, diketahui hambatan yang berasal dari luar diri guru BK untuk melaksanakan instrumen non-tes dalam pelayanan BK di sekolah adalah tidak tersedia dan terbatasnya waktu yang terjadwal untuk pelayanan BK di kelas.

\section{Usaha Guru BK Mengatasi Hambatan untuk Melaksanakan Instrumen Non-Tes dalam Pelayanan BK di Sekolah}

Berdasarkan hasil penelitian yang dilakukan, dapat disimpulkan bahwa ratarata guru BK yang sudah memberikan angket telah melakukan berbagai usaha mengatasi hambatan untuk memeberikan angket dalam pelayananan BK di sekolah. Namun, sebanyak 7,7\% guru BK tidak melakukan usaha dalam mencari informasi dari pakar atau orang yang ahli di bidang ini jika tidak memahami tata cara pemberian angket.

Menurut Prayitno (2006:9) bahwa "penyelenggara instrumen non-tes pada umumnya lebih terbuka, dengan catatan si (calon) penyelenggara itu harus terlebih dahulu berlatih diri sehingga benar-benar mampu menyelenggarakan sesuai dengan syarat-syarat pengukuran yang baik". Dalam hal ini, untuk dapat memahami tata cara pemberian angket maka guru BK dapat berlatih dan mencari informasi dari dari orang yang ahli dibidang ini.

Selanjutnya, rata-rata guru BK yang sudah melaksanakan sosiometri telah melakukan berbagai usaha mengatasi hambatan untuk melaksanakan sosiometri dalam pelayananan BK di sekolah. Namun, sebanyak 15,8\% guru BK tidak bekerjasama dengan kepala sekolah, wali kelas serta guru mata pelajaran dalam penyediaan sarana dan prasarana penunjang pelaksanaan sosiometri.

Menurut Dewa Ketut Sukardi (1996:64) layanan bimbingan dan konseling yang efektif tidak mungkin terlaksana dengan baik tanpa adanya kerjasama guru pembimbing dengan pihak-pihak yang terkait di dalam maupun di luar sekolah. Demikian juga dengan pelaksanaan sosiometri, guru BK hendaknya dapat bekerjasama dengan pihak-pihak terkait seperti kepala sekolah, wali kelas dan guru mata pelajaran agar pelaksanaan sosiometri dapat terlaksana dengan baik.

Jadi, dapat disimpulkan bahwa rata-rata guru BK telah melakukan berbagai usaha untuk mengatasi hambatan, namun masih ada guru BK yang tidak bekerjasama dengan kepala sekolah, wali kelas serta guru mata pelajaran dalam penyediaan sarana dan prasarana penunjang serta tidak mau mencari informasi dari pakar atau orang yang ahli di bidangnya jika tidak memahami tata cara untuk melaksanakan instrumen non-tes.

\section{KESIMPULAN}

Berdasarkan hasil analisis data yang telah dibahas maka dapat diambil kesimpulan sebagai berikut : (1) hambatan yang berasal dari dalam diri guru BK untuk melaksanakan instrumen non-tes dalam pelayanan BK di sekolah adalah kurang terampil dalam menggunkan program kompter dan sulit menjelaskan petunjuk 
pengisian instrumen non-tes kepada siswa, (2) hambatan yang berasal dari luar diri guru BK untuk melaksanakan instrumen non-tes dalam pelayanan BK di sekolah adalah tidak tersedia dan terbatasnya waktu yang terjadwal untuk pelayanan BK di kelas, dan (3) Usaha yang dilakukan guru BK mengatasi hambatan untuk melaksanakan instrumen non-tes dalam pelayanan BK di sekolah adalah rata-rata guru BK telah melakukan berbagai usaha untuk mengatasi hambatan, namun masih ada guru BK yang tidak bekerjasama dengan kepala sekolah, wali kelas serta guru mata pelajaran dalam penyediaan sarana dan prasarana penunjang serta tidak mau mencari informasi dari pakar atau orang yang ahli di bidangnya jika tidak memahami tata cara untuk melaksanakan instrumen non-tes.

\section{REFERENSI}

Dewa Ketut Sukardi.1996. Pengelolaan Layanan Bimbingan dan Konseling. Jakarta: Rineka Cipta.

Gantina Komalasari, dkk. 2011. Assesmen Teknik Non-Tes dalam Perspektif BK Komperhensif. Jakarta: PT. Indeks.

Izaak Latunussa. 1988. Penelitian Pendidikan Suatu Pengantar. Jakarta: Depdikbud.

Jefi Rangga Permaga. 2012. Pengadministrasian Insntrumen Non-Tes oleh Guru BK dalam Pemberian Layanan BK di SMA N 1 Kota Pariaman (Skripsi). Padang: BK FIP UNP.

Nana Sudjana dan Ibrahim. 2011. Penilaian Hasil Proses Belajar Mengajar. Bandung: PT. Remaja Rosdakarya.

Panduan Pengembangan Diri untuk Satuan Pendidikan Dasar dan Menengah Tahun 2006.

Panduan Pengembangan Diri untuk Satuan Pendidikan Dasar dan Menengah Tahun. 2006. Seri Kegiatan Pendukung Konseling (P1-P6). Padang: BK FIP UNP.

Soetjipto. 1994. Profesi Keguruan. Jakarta: Rineka Cipta.

Tulus Winarsunu. 2002. Statistik dalam Penelitian Psikologi dan Pendidikan. Malang: UMM Pers. 